\title{
Starvation at birth impairs germ cell cyst breakdown and increases autophagy and apoptosis in mouse oocytes
}

\author{
Yong-Yong Wang ${ }^{1,2}$, Yuan-Chao Sun ${ }^{2}$, Xiao-Feng Sun ${ }^{1,2}$, Shun-Feng Cheng ${ }^{2}$, Bo Li ${ }^{3}$, Xi-Feng Zhang ${ }^{2}$, Massimo De Felici ${ }^{4}$ and \\ Wei Shen ${ }^{*, 2}$
}

The female reproductive lifespan is largely determined by the size of primordial follicle pool, which is established following germ cell cyst breakdown around birth. Almost two-third of oocytes are lost during germ cell cysts breakdown, following autophagic and apoptosis mechanisms. To investigate a possible relationship between germ cell cyst breakdown and nutrition supply, we established a starvation model in mouse pups at birth and evaluated the dynamics of cyst breakdown during nutrient deprivation. Our results showed that after $36 \mathrm{~h}$ of starvation between 1.5 and 3 d.p.p., indicators of metabolism both at systemic and ovarian level were significantly altered and the germ cell cyst breakdown markedly decreased. We also found that markers of oxidative stress, autophagy and apoptosis were increased and higher number of oocytes in cyst showing autophagic markers and of TUNEL-positive oocytes and somatic cells were present in the ovaries of starved pups. Moreover, the proliferation of pre-granulosa cells and the expression of the oocyte-specific transcription factor Nobox were decreased in such ovaries. Finally, we observed that the ovaries of the starved pups could recover a normal number of follicles after about 3 weeks from re-feeding. In conclusion, these data indicate that nutrient deficiency at birth can generate a number of adaptive metabolic and oxidative responses in the ovaries causing increased apoptosis both in the somatic cells and oocyte and autophagy mainly in these latter and leading to a delay of germ cell cyst breakdown and follicle assembly.

Cell Death and Disease (2017) 8, e2613; doi:10.1038/cddis.2017.3; published online 9 February 2017

Germ cell cysts refer to a cluster of interconnected germ cells resulting from incomplete mitotic cytokinesis. ${ }^{1-3}$ In the mouse, germ cells form cysts from 10.5 to 13.5 days post coitum (d.p.c.) during the period of the primordial germ cell (PGC) proliferation in both sexes. ${ }^{4,5}$ In female mice, cysts partially fragment prior to meiosis and gradually decrease in oocyte number throughout 17.5 d.p.c. to 4.0 days post partum (d.p.p.). ${ }^{6}$ In Drosophila, the mechanisms of germ cell cyst formation and its role in oogenesis have been elucidated. At first, one germline stem cell undergoes four times mitosis to form a 16-cell cyst, only one of these develops into an oocyte while the other 15 cells act as nurse cells. Such cells provide nutrients, proteins, mRNAs and organelles for the developing oocyte, transport their contents into the oocyte and undergo programmed cell death (PCD). ${ }^{7,8}$

Likewise in the mouse, some oocytes within a cyst appear to receive nutrients and organelles from neighboring oocytes fated to undergo death. ${ }^{9,10}$ It is not clear, however, whether oocytes in cysts die during or after cyst breakdown. In one model, one oocyte of a cyst dies following apoptosis and the large cyst breaks into two smaller cysts; this is repeated until a few individual oocytes remain. ${ }^{11}$ However, another study showed that cyst breakdown and apoptosis do not precisely coincide indicating that apoptosis is unlikely to be the major cause of cyst breakdown and that most of the oocytes actually die after cyst breakdown. ${ }^{6}$ Oocyte death during the fetal and early postnatal period has been described to occur by multiple causes and processes including apoptosis and autophagy. ${ }^{12-15}$ Several lines of evidence demonstrate that inducers of oxidative stress may act as signaling molecules in the pathway of apoptosis in several, if not all, cells and tissues. ${ }^{16,17}$ Oxidative stress occurs when the normal cellular redox balance is disturbed, resulting in dysregulation of redox-regulated processes and/or oxidative damage to cellular structures. ${ }^{18,19}$ As a matter of fact, oxidative stress can impair the ovary's function and normal development of follicles and has been associated with polycystic ovary syndrome (PCOS). ${ }^{20,21}$ Actually, in rodent models, increased ROS levels induce rapid primordial follicle loss and apoptosis in antral follicles. ${ }^{22}$ Whatever the exact mechanisms of oocyte apoptosis, in the mouse, more than twothird of oocytes die before and a few days after birth. At this time, cyst disappearance is concomitant with the formation of the primordial follicles (PFs). Processes extending from somatic cells have been observed between oocytes suggesting that somatic cells may physically separate oocytes. ${ }^{11}$ Physiologically, the size of the PF pool will largely determine the reproductive lifespan of female mammals.

The processes of cyst breakdown and follicle assembly likely involve communication between oocytes and pre-granulosa cells that is mediated and regulated by several factors. As a

\footnotetext{
${ }^{1}$ College of Life Sciences, Qingdao Agricultural University, Qingdao 266109, China; ${ }^{2}$ College of Animal Science and Technology, Institute of Reproductive Sciences, Qingdao Agricultural University, Qingdao 266109, China; ${ }^{3}$ Chengguo Station of Animal Husbandry and Veterinary, Laizhou 261437, China and ${ }^{4}$ Department of Biomedicine and Prevention, University of Rome Tor Vergata, Rome 00133, Italy

${ }^{*}$ Corresponding author: W Shen, College of Animal Science and Technology, Institute of Reproductive Sciences, Qingdao Agricultural University, 700 Changcheng Road, Chengyang, Qingdao 266109, China. Tel: +860 532 88030246; Fax: +860 532 86080773; E-mail: wshen@qau.edu.cn or shenwei427@163.com

Received 12.7.16; revised 02.1.17; accepted 03.1.17; Edited by GM Fimia
} 
a
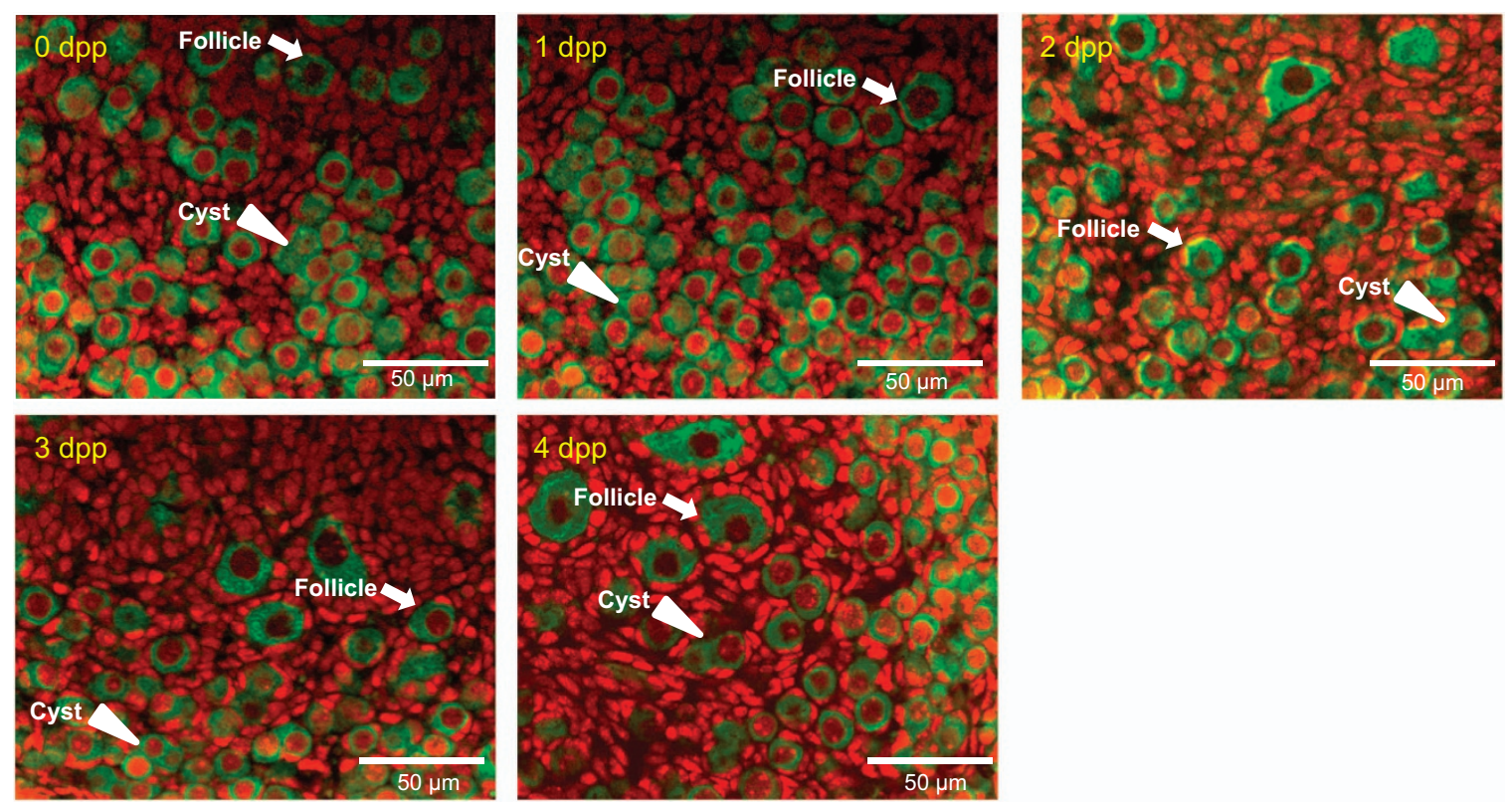

b

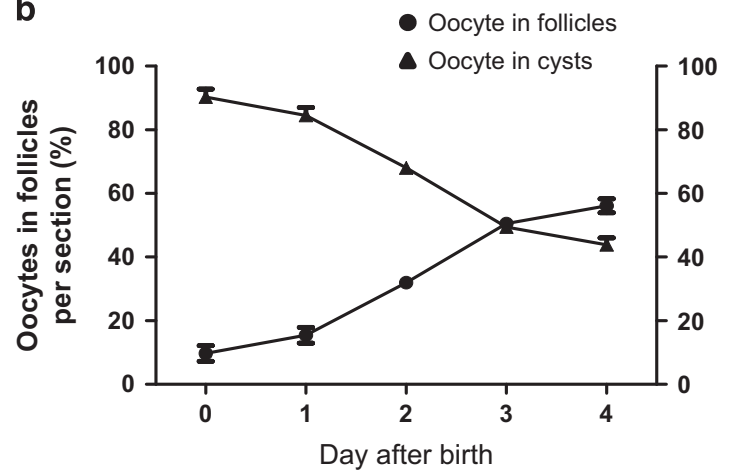

C

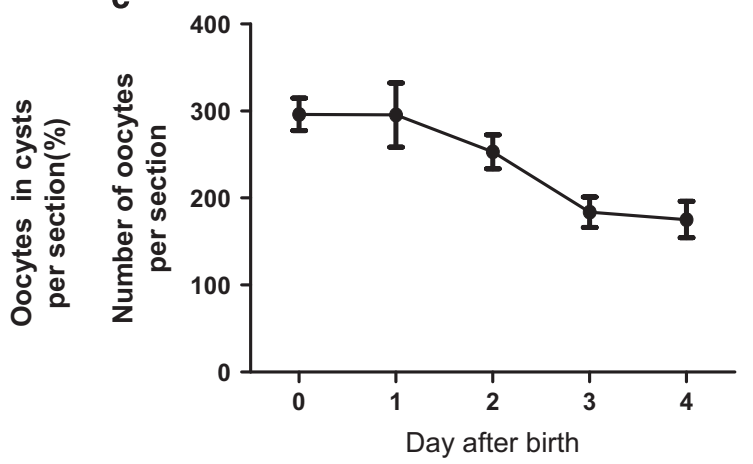

Figure 1 Dynamics of germ cell cyst breakdown. (a) Representative IF for oocytes with MVH (green) in tissue sections of ovaries at 0-4 d.p.p. Plenty of oocytes remaining within cysts (arrowheads) at $0-1$ d.p.p., and quantification of oocytes were surrounded by pre-granulosa cells and formed primordial follicles (arrows) at 3-4 d.p.p. Scale bars: $50 \mu \mathrm{m}$. (b) Percent of oocytes in follicles through 0 to 4 d.p.p.; note acceleration of cyst breakdown between 1 and 3 d.p.p., and quantification of oocyte number at $0-4$ d.p.p.; note a marked decrease of the oocyte number between 1 and 3 d.p.p. (c) Number of oocytes per section in mouse ovaries of 0 to 4 d.p.p. Results are presented as mean \pm S.D. All the experiments were repeated at least three times

matter of fact, a number of compounds can influence cyst breakdown and consequently the pool of PFs. In vivo and in vitro exposure of neonatal mouse ovaries to $\mathrm{E} 2$, progesterone or phytoestrogens (i.e., genistein), inhibits cyst breakdown and PF assembly. ${ }^{23,24}$ Synthetic forms of estrogens, such as diethylstilbestrol (DES), bisphenol-A (BPA) and ethinyl estradiol (EE), also block cyst breakdown and alter PF formation. ${ }^{25-27}$ Disruption of Notch signaling by pharmacological inhibition, global deletion of Notch2 or Hes1 (a downstream mediator of Notch signaling) or conditional knockout of $L$ fng (a negative modulator of Notch) or Hes1 in somatic cells, result in abnormal oocyte maturation and multi-oocyte follicles (MOFs) ${ }^{28-31}$ Other signaling molecules and several growth factors appear to have a role in follicle assembly. Among these, the stem cell factor (SCF, also known as Kit ligand, $\mathrm{KL})^{32-35}$ and neurotrophins ${ }^{36-38}$ favor such process. Mutants for either bone morphogenetic protein 15 (BMP15) or growth differentiation factor 9 (GDF9), have ovaries with a significant proportion of MOFs. ${ }^{39}$ Both BMP15 and GDF9 are secreted by the oocyte early in ovarian differentiation, supporting the notion that signals from the oocyte to the granulosa cells are important for cyst breakdown and follicle formation. Mouse ovaries exposed to another TGF $\beta$ family member, activin A, showed an increased number of PFs. ${ }^{40}$ Sustaining a positive role of activin in PF formation, more MOFs were observed in mice overexpressing the activin antagonist, inhibin $\mathrm{B}^{41}$ In addition, activin subunit expression is reduced in neonatal mice treated with E2, which blocks cyst breakdown. ${ }^{42}$ Mutants of another activin antagonist, follistatin, also have defects in oocyte development including a delay in cyst breakdown and follicle formation, ${ }^{43}$ while FST288, the strongest activin-neutralizing isoform, impaired germ cell nest breakdown and primordial follicle assembly by inhibiting pre-granulosa cell proliferation. ${ }^{44}$ The last TGF $\beta$ family member that has been implicated in follicle assembly is anti-Mullerian hormone (AMH). $\mathrm{PF}$ assembly is reduced in newborn rat ovaries treated with $\mathrm{AMH}$ while oocyte number is greater than controls. ${ }^{45} \mathrm{~A}$ study using 
a

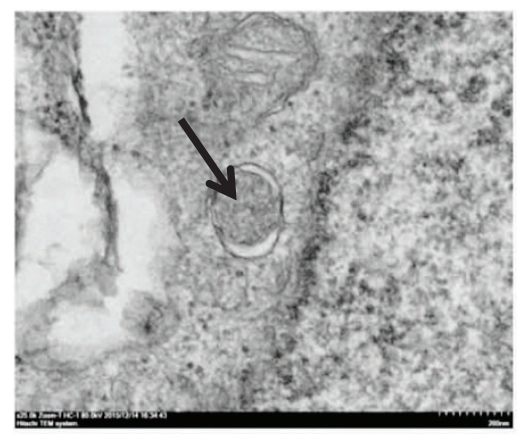

c

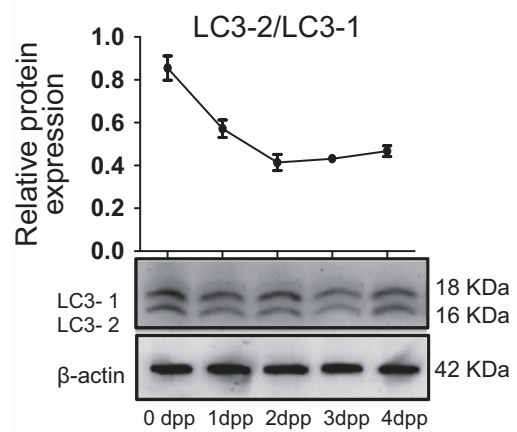

b
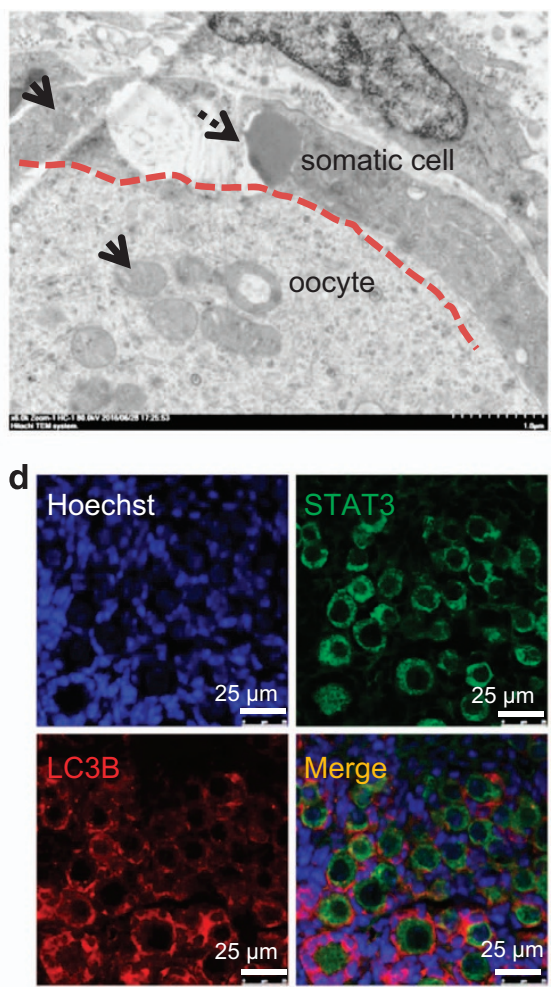

Figure 2 Morphological characteristics and autophagic markers in ovaries and oocytes at 0-4 d.p.p. (a) An autophagosome (arrow) in the oocyte cytoplasm. TEM, scale bar: $200 \mathrm{~nm}$. (b) Numerous mitochondria (arrows) in the oocyte cytoplasm. Lipid droplets (arrows) in the cytoplasm of a somatic cell around oocytes. TEM, scale bars: $1 \mu \mathrm{m}$. (c) WB for LC3-1 to LC3-2 in ovaries of 0-4 d.p.p. During autophagy, cytosolic LC3-1 is conjugated to phosphatidylethanolamine to form LC3-phosphatidylethanolamine conjugate (LC3-2), which is recruited to autophagosomal membranes. (d) IF for LC3B (red) and STAT3 (green) in 3 d.p.p. ovaries

mouse ovary organ culture implicates FSH in promoting cyst breakdown and PF formation. ${ }^{46}$ Finally, a study in the mouse ovary showed that cyst breakdown requires the activity of c-Jun $\mathrm{N}$-terminal kinases (JNKs) that are likely necessary to downregulate $\mathrm{E}$-cadherin expression in oocytes. ${ }^{47}$

A number of transcription factors appear also to be important for PF formation. Mutant mice for the gene encoding the aryl hydrocarbon receptor (AHR), a basic helix loop helix (bHLH) transcription factor, form follicles at a faster rate than normal. ${ }^{48,49}$ Mice lacking the factor in germline alpha (Figla), also encoding a bHLH protein, begin to lose oocytes at birth and oocytes still present are not enclosed in PFs. ${ }^{50}$ Disruption of Nobox (an oocyte-specific homeobox gene), results in increased mouse oocyte loss and a delay in cyst breakdown. ${ }^{51,52}$ Mice mutant for Foxl2, (a winged-helix forkhead transcription factor), are sterile with germ cell cysts that do not breakdown. ${ }^{53}$ Finally, siRNA knockdown of heterogeneous nuclear ribonucleoprotein $\mathrm{K}$ in rat ovary organ culture caused a block in cyst breakdown and follicle formation. ${ }^{54}$ Recent data showed that PCNA (proliferating cell nuclear antigen) can regulate primordial follicle assembly by promoting apoptosis of oocytes in fetal and neonatal mouse ovaries. ${ }^{55}$

Many animals alter their reproductive strategies in response to environmental stress. For example, in female Drosophila and Caenorhabditis elegans, starvation activates apoptotic checkpoints and autophagy in oogenesis and reduces the production of mature oocytes. ${ }^{56,57}$ In the perilous hours immediately after birth, a newborn mammal must survive the sudden loss of food supply from its mother. Under normal circumstances, newborns increase a metabolic response to ward off starvation until feeding occurs. Under these conditions, autophagy may become essential for viability of various tissues. ${ }^{58}$ The observation that in mouse the most part of the cyst breakdown occurring from 2 to 5 d.p.p., parallels the time when fully nutrient supply is restored by milk feeding, prompted us to investigate the influence of starvation on this process and PF assembly.

\section{Results}

Oocytes in cysts show morphological and molecular markers of autophagy. In a first series of experiments, we characterize the dynamics of germ cell cyst breakdown in mouse ovaries from 0 to 4 d.p.p. Immunolocalization of the oocytes with the germ cell specific marker MVH (mouse Vasa homolog) in tissue sections, revealed that while almost all oocytes were located in germ cell cysts (indicated by arrowheads) at 0 d.p.p., more than half of them were individually enclosed into follicles (indicated by arrows) at 4 d.p.p. (Figures 1a and b). Between 1 and 3 d.p.p., germ cell cyst breakdown was intense and associated with a major loss of oocytes (Figures $1 \mathrm{~b}$ and $\mathrm{c}$ ). 
a
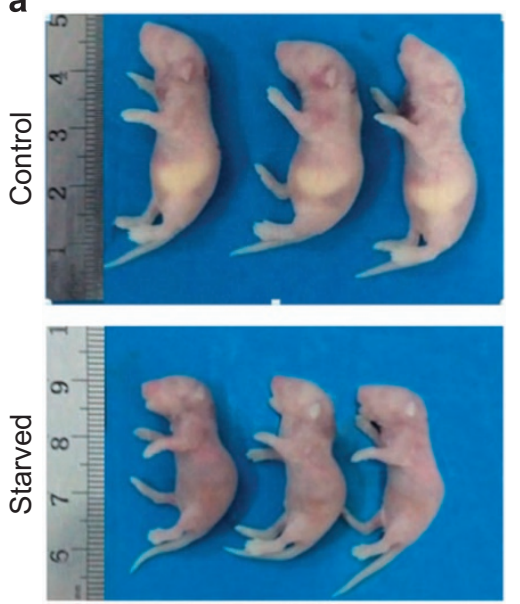

b

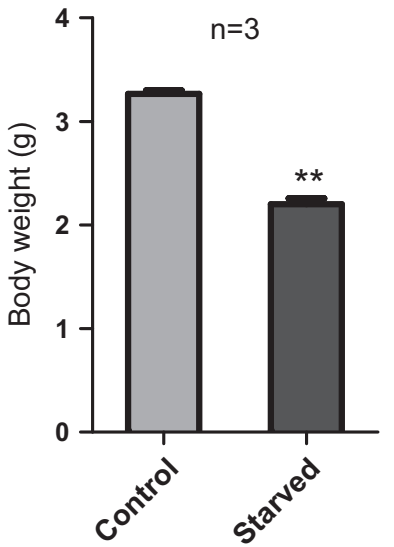

C

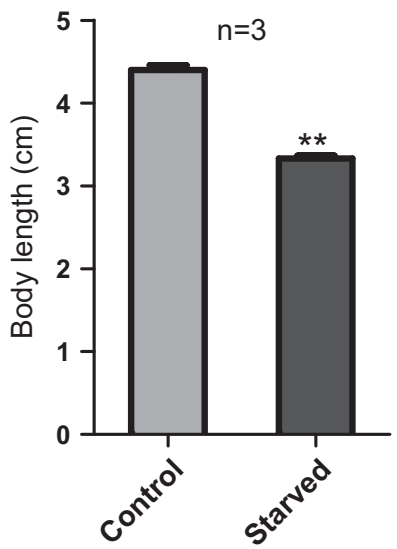

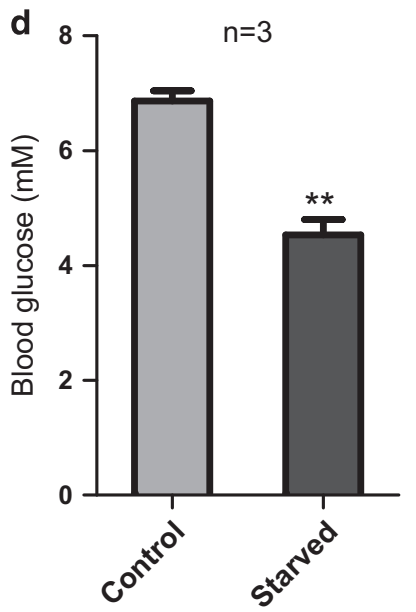

e

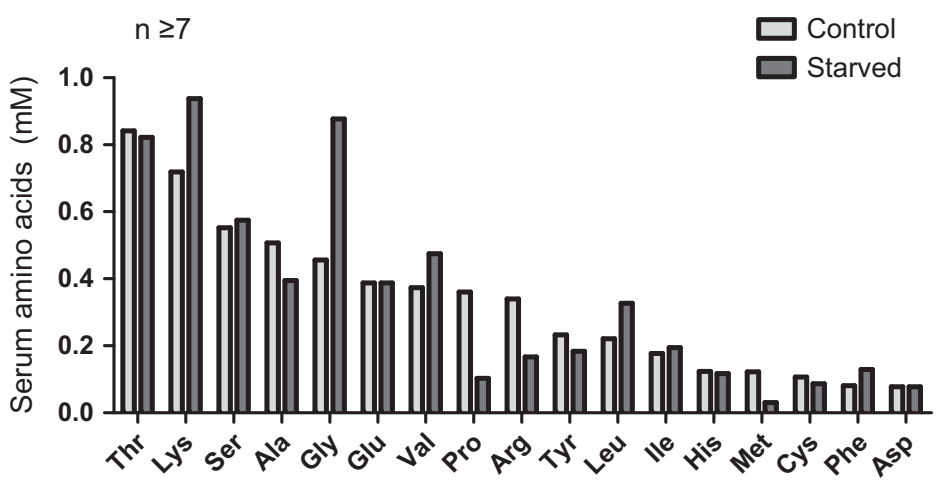

Figure 3 Systemic effects of pups starvation. (a) Photograph of starved pups compared with normal littermate. (b and $\mathbf{c}$ ) Body weight and length of starved and control pups $(n=3)$. (d) Concentration of blood glucose in starved and control pups $(n=3)$. (e) Concentrations of 17 amino acids in the serum of starved and control pups $(n=13)$. The results are presented as mean \pm S.D. ${ }^{\star} P<0.05 ;{ }^{* *} P<0.01$

TEM observations showed a frequent presence of autophagosomes, recognized for their characteristic spherical vesicle with double-layer membranes, suggesting macroautophagy, in the oocyte cytoplasm and of large number of mitochondria in some oocytes within cysts at 3 d.p.p. (Figure 2a, Supplementary Figures S1A and B). On the other hand, the somatic cells surrounding the oocytes showed less numerous mitochondria and smaller size lipid droplets often closely surrounded by mitochondria (Figure 2b). The expression of the autophagosome membrane-associated light chain 3-2 protein (LC3-2), in protein extracts from 0 to 4 d.p.p. ovaries was indicative of ongoing autophagy, while the relatively rapid decrease of the value of the ratio LC3-2/LC3-1 (the LC3 cytosolic form) from 0 to 3-4 d.p.p. suggested higher level of autophagy at the beginning of cyst breakdown (Figure 2c). Moreover, double IF staining for LC3B and the oocyte marker STAT3 of tissue sections of 3 d.p.p. ovaries revealed that most of the autophagic protein was localized in oocytes within cysts, primordial follicles and the granular cells of primary follicles (Figure 2d, Supplementary Figures S1C and D).
Pup starvation for $36 \mathrm{~h}$ impairs primordial follicle assembly. To investigate whether nutrient supply can affect germ cell cyst breakdown and PF assembly, we first established a starvation model by depriving pups of nutrients for $36 \mathrm{~h}$ from 1.5 d.p.p. to 3 d.p.p. We observed that besides the overall physical appearance of emaciation (Figure 3a), the weight and length of the body of starved mice were significantly decreased in comparison with controls $(P<0.01$; Figures $3 \mathrm{~b}$ and $\mathrm{c}$ ). Furthermore, in mice of the experimental group, the concentration of glucose in the blood sharply lowered $(P<0.01)$, while the amino acid metabolism appeared altered (Figures $3 d$ and $e$ ).

In the ovaries of the starved pups, the size and the transcript level of genes involved in metabolic pathways resulted also clearly altered. As a matter of fact, the ovaries of these pups were smaller and weighted significantly lesser than control (Figure 4a). Moreover, the lack of alteration of the mRNA level of Glut1, a gene encoding a major glucose transporter (Figure 4b), the decreased levels of transcripts of three genes encoding proteins of fatty acid synthesis such as Fabp5, Cpt2 
a
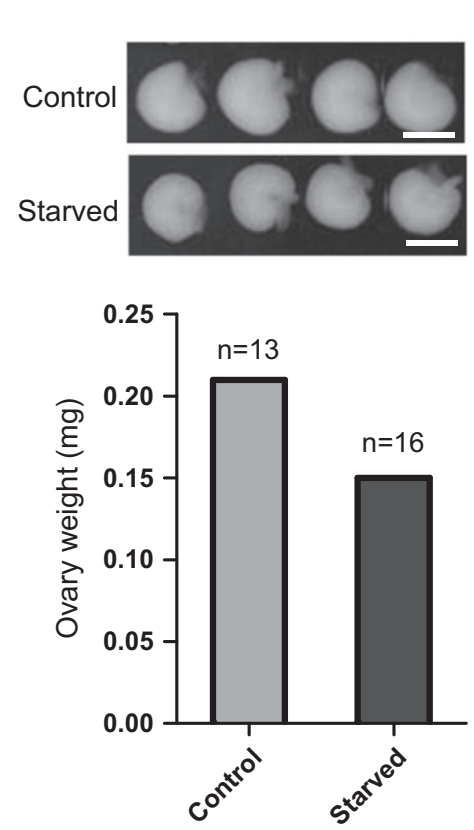

b
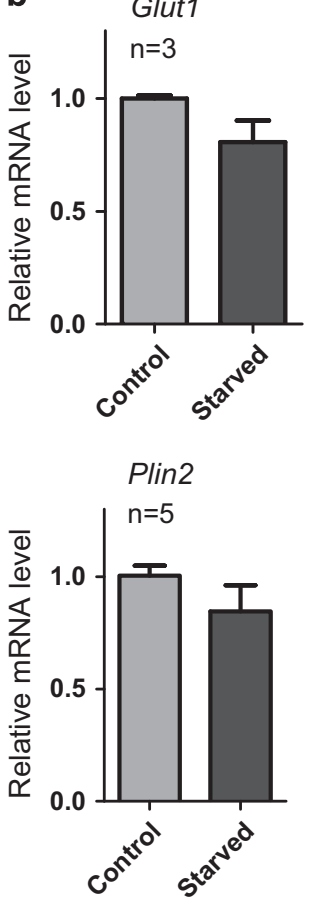

Slc7a5
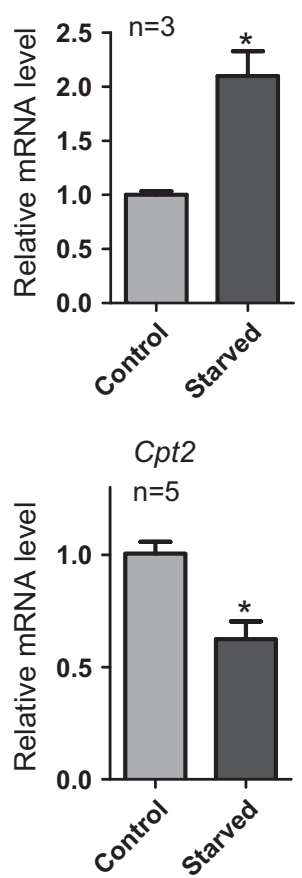
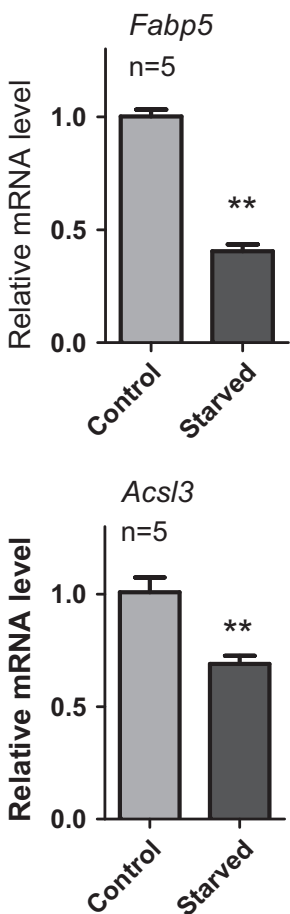

Figure 4 Alteration of size and transcript level of genes involved in metabolic pathways of starved pup ovaries. (a) Top: photograph of ovaries of starved and control pups. Scale bars: $500 \mu \mathrm{m}$. Bottom: weight of ovaries from starved and control pups. (b) Quantitative RT-PCR of mRNA of the metabolism relevant genes Glut1, Slc7a5, Plin2, Fabp5, Cpt2 and $A c s / 3$. The results are presented as mean \pm S.D. All the experiments were repeated at least three times. ${ }^{*} P<0.05 ;{ }^{* *} P<0.01$.

and $A c s / 3$, although not of Plin2 $(P<0.05$ or $P<0.01$; Figure $4 b$, Supplementary Figure S4), and the increased level of mRNA of Slc7a5, encoding a transporter of large neutral amino acids $(P<0.01$; Figure $4 \mathrm{~b})$, suggested compensatory changes in critical physiologies and defects in energy allocation, storage or utilization.

By counting the number of oocytes in cysts or enveloped individually into follicles in tissue sections of ovaries at 3 d.p.p., we found that the normal dynamics of cyst breakdown and PF formation was significantly impaired in starved pups (Figure 5a). Actually, in the ovaries of such group, the number of oocytes in cysts was higher and that in follicles lower in comparison with control, although the total number of oocyte did not change (Figure 5b).

Markers of oxidative stress, autophagy and apoptosis are increased in ovaries of starved pups. To determine whether the defects in cyst breakdown and follicle assembly occurring in the ovaries of starved animals were associated to changes in processes such as oxidative stress, autophagy and apoptosis, we analyzed the mRNA level and/or proteins of the anti-oxidative enzymes GPX1, SOD1, CLRX1 and TXNRD1, of apoptotic Bax and major proteins such as BCL2 and BAX and of the autophagic proteins LC3-2 and BECLIN1. Quantitative real-time PCR showed significant $(P<0.05)$ increased transcripts of Sod1, Clrx1 and Txnrd1 and of the Bax/Bcl2 mRNA ratio in starved ovaries (Figure 6a, Supplementary Figure S2). This later was confirmed also at protein level (Figure 6b). About the autophagic proteins, the number of oocytes in cysts showing spots of IF LC3-2 positivity was higher in starved than in control ovaries (Supplementary
Figure S3A). Moreover, the level of BECLIN1 protein, evaluated by western blot (WB), decreased in ovaries after $12 \mathrm{~h}$ but returned to the control level after $24-36 \mathrm{~h}$ of starvation (Supplementary Figure S3B). Compared with control group, the ratio of $\mathrm{Bax} / \mathrm{Bcl} 2$ in starvation group was increased in both the gene and protein levels. Surprisingly, number of TUNELpositive cells was really small, there were rare cells found to be positive for apoptotic markers in both the starvation group and control group, especially in the control group (Figures $6 \mathrm{c}$ and d; Supplementary Figure S3C). And similar results could be found in previous publications. ${ }^{11,14}$

At the same time, the number of pre-granulosa cells positive for the nuclear PCNA staining, generally associated to cell proliferation, was significantly reduced in starved in comparison with normal ovaries $(P<0.05$; Figures $6 a$ and b). Moreover, among four oocyte-specific transcription factors analyzed such as Lhx8, Sohlh2, Figla and Nobox, only the latter one resulted significantly reduced at protein level (Figures 5c-f and Supplementary Figure S2).

Reversibility of the starvation effect on the ovarian follicle pool. We finally verified whether the ovaries of pups re-feeding after starvation were able to recover a normal PF pool. In this regard, we observed that after re-feeding, pups regained body weight and length, and at 21 d.p.p. (18 days from starvation), no significant difference remained between the control and starved animals (Figures 7a and $b$ ). At this time, the number of PF and of other stages as well, in the starved and normal ovaries were comparable (Figures 7c and d). 


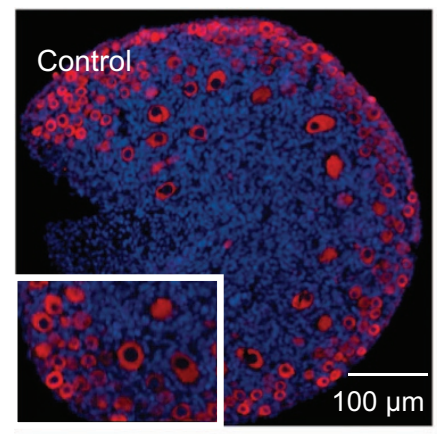

c
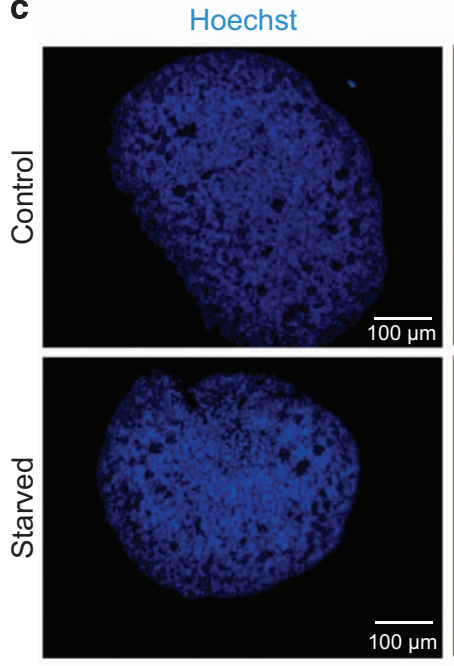

d

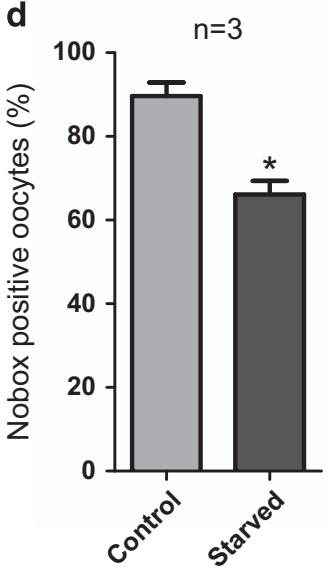

e

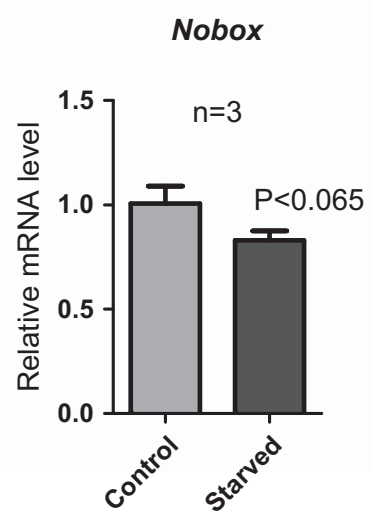

b
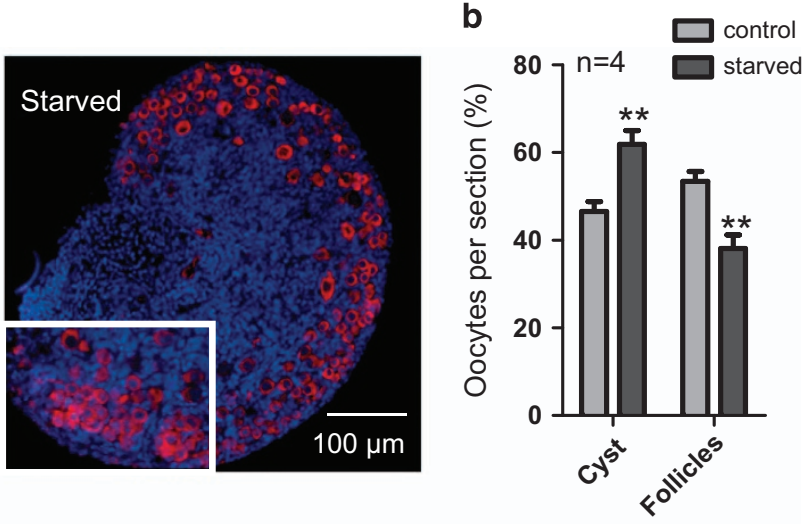

NOBOX
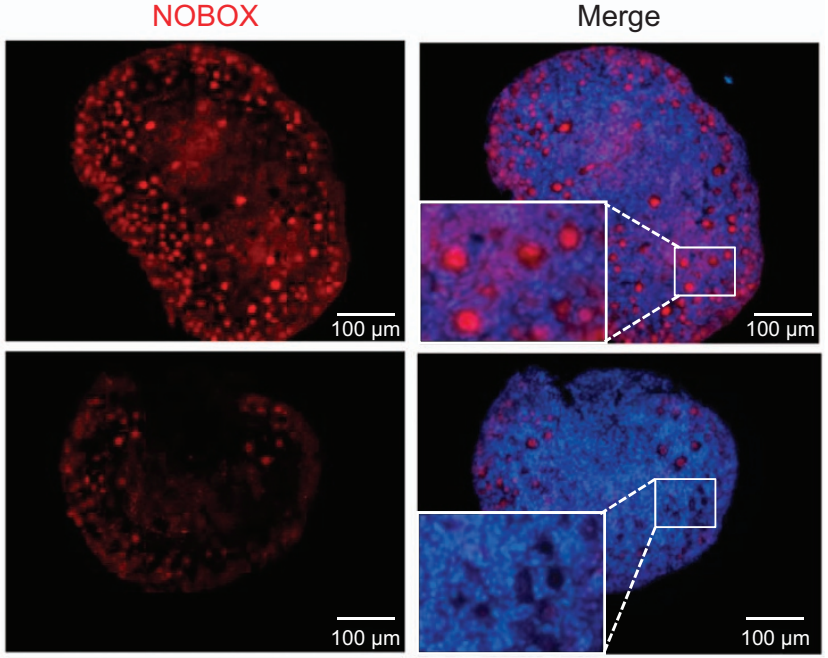

f
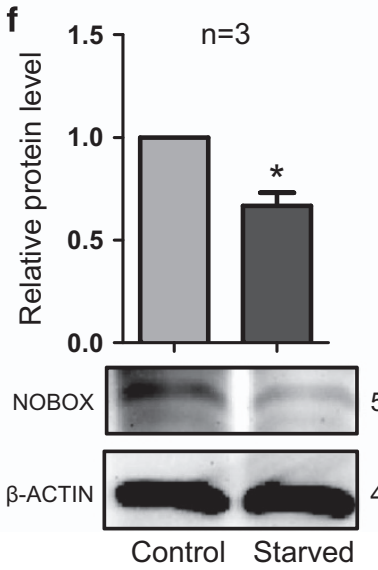

58 KDa

$42 \mathrm{KDa}$

Figure 5 Pup starvation impairs germ cell cyst breakdown and follicle assembly. (a) Representative IF for the germ cell marker MVH in tissue sections of 3 d.p.p. ovaries from control and starved pups. Note that while in the control ovary, the most part of oocytes are formed cortical and medullary PFs, those in the starved ovary remained in cortical cysts. Scale bars: $100 \mu \mathrm{m}$. (b) Quantification of the number of oocytes in cysts and in follicles in 3 d.p.p. control and starved ovaries. (c) Representative IF for the oocyte-specific transcription factor NOBOX in tissue sections of 3 d.p.p. ovaries from control and starved pups. Scale bars: $100 \mu \mathrm{m}$. (d) Percentage of oocyte showing strong NOBOX staining in ovary tissue sections. (e) Quantitative RT-PCR for Nobox mRNA levels in control and starved ovaries. (f) Level of NOBOX protein in control and starved ovaries. The results are presented as mean \pm S.D. All the experiments were repeated at least three times. ${ }^{\star} P<0.05 ;{ }^{* *} P<0.01$

\section{Discussion}

The results of our first analyses concerning the dynamics of germ cell cyst breakdown, showed that a peak in this process occurred between 1 and 3 d.p.p. and was associated to a marked decrease of the oocyte number. Moreover, morphological and molecular markers of autophagy were found in some oocytes inside cysts. All together, these data support the existence of a relationship between cyst breakdown and 
a
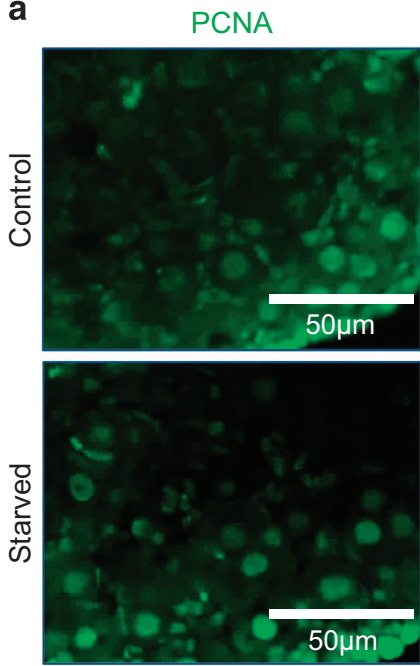

b

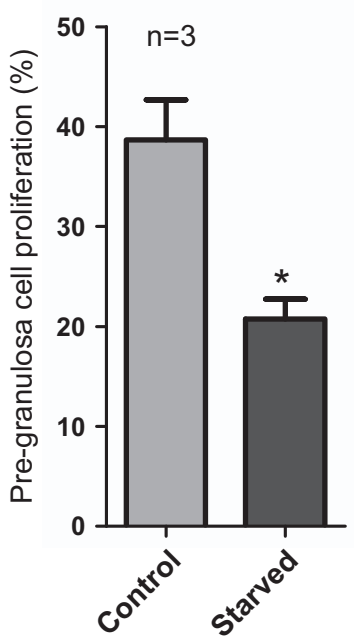

Pl
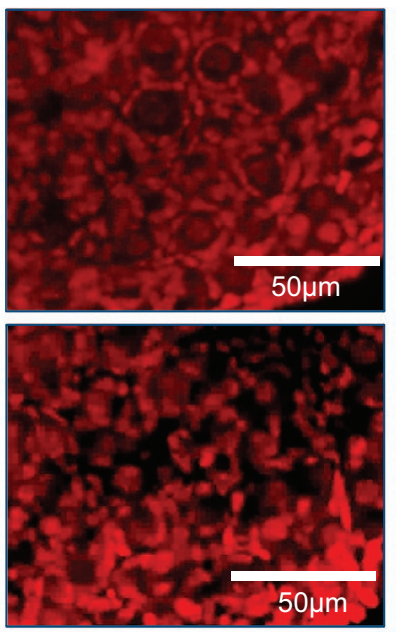
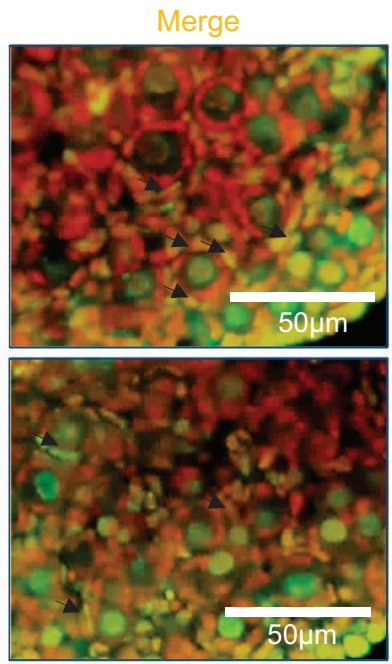

d
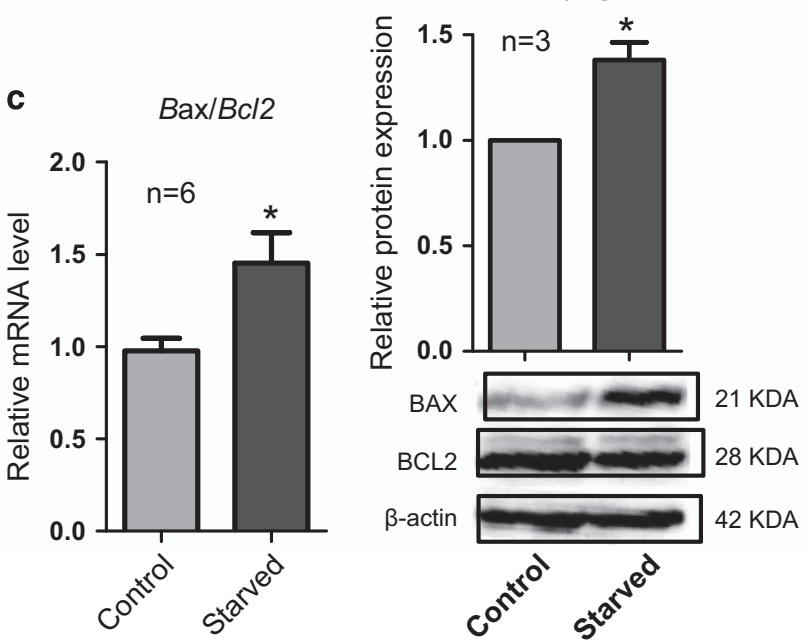

Figure 6 Proliferation and apoptotic markers in control versus starved ovaries. (a) PCNA histochemistry (green) in representative tissue sections of ovaries from normal and starved pups. (b) Percentage of relative pre-granulosa cell proliferation: PCNA-positive pre-granulosa cells/total oocytes in one section. (c) Quantitative RT-PCR for apoptosis relevant genes Bax/Bcl2. (d) Increased BAX/BCL2 protein ratio in starved ovaries in comparison with control. The results are presented as mean \pm S.D. All the experiments were repeated at least three times. ${ }^{\star} P<0.05 ;{ }^{*} P<0.01$

oocyte degeneration but do not clarify whether oocyte death precedes, is concomitant or occurs after such process. At the same time, the presence of autophagic markers in oocytes within cysts, primordial follicles and the granulosa cells of primary follicles, but not inside primary follicles, suggests that, under normal condition, activation in one or a few cystic oocytes of autophagy perhaps related to a large number of mitochondria observed at TEM, can be a prerequisite for their survival after cyst breakdown. In line with our observations, some of the mouse oocytes in cysts have been reported to acquire many organelles, including mitochondria, and other cytoplasmic components before primordial follicle formation. ${ }^{10}$ These materials, derived by transfer from interconnected oocytes, could be used as material for autophagy. Under starvation condition, autophagy could be exacerbated and ultimately lead to apoptosis. Actually, several evidences are accumulating that autophagy and apoptosis may be triggered by common upstream signals, sometimes converging in combined autophagy and apoptosis. The alteration of metabolic parameters and the increased expression of a number of enzymes involved in oxidative stress alongside with enhance of both autophagic and apoptosis markers in the ovaries from starved pups, testify a general cellular stress induced by the nutrient deprivation as the trigger of the cell death processes. Under such conditions, both pre-granulosa cell proliferation and expression of some oocyte transcription factors (i.e., Nobox), crucial for follicle assembly, appeared also to be impaired. This might explain the reduced rate of cyst breakdown. As Nobox is expressed mostly in primary (growing) oocytes and no change in transcripts level of other oocyte-specific genes such as Lhx8, Sohlh2, Figla occur, oocyte growth could be also impaired in starved ovaries. Interestingly, the adverse effects of starvation on the ovaries appeared reversible. Actually, after about 3 weeks from pup refeeding, the ovaries regained a normal number of follicles. This could indicate that cyst breakdown was only delayed and 
a
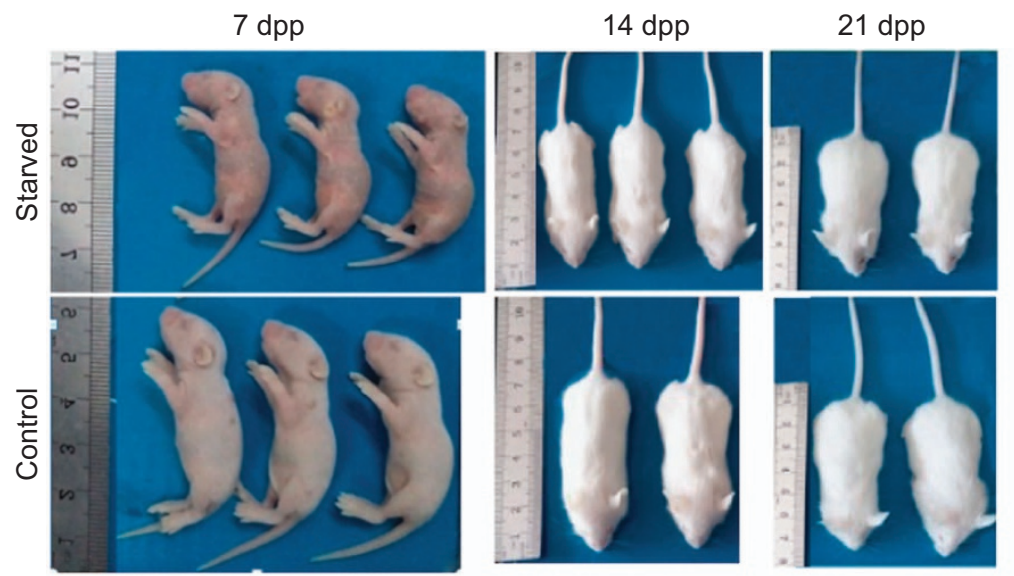

b
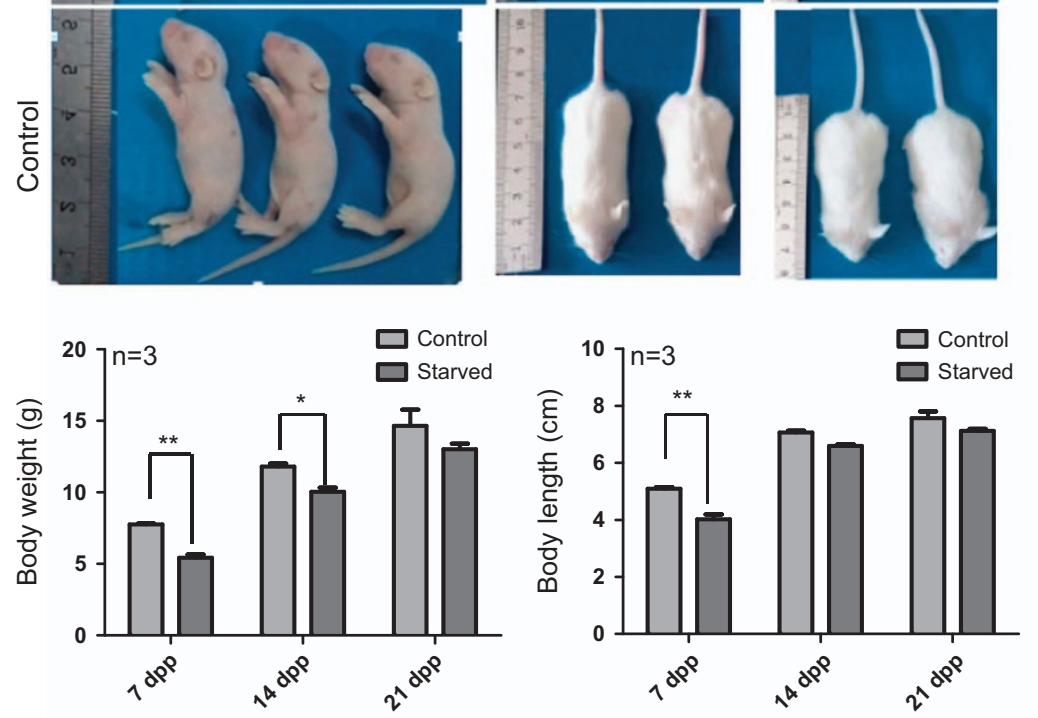

C
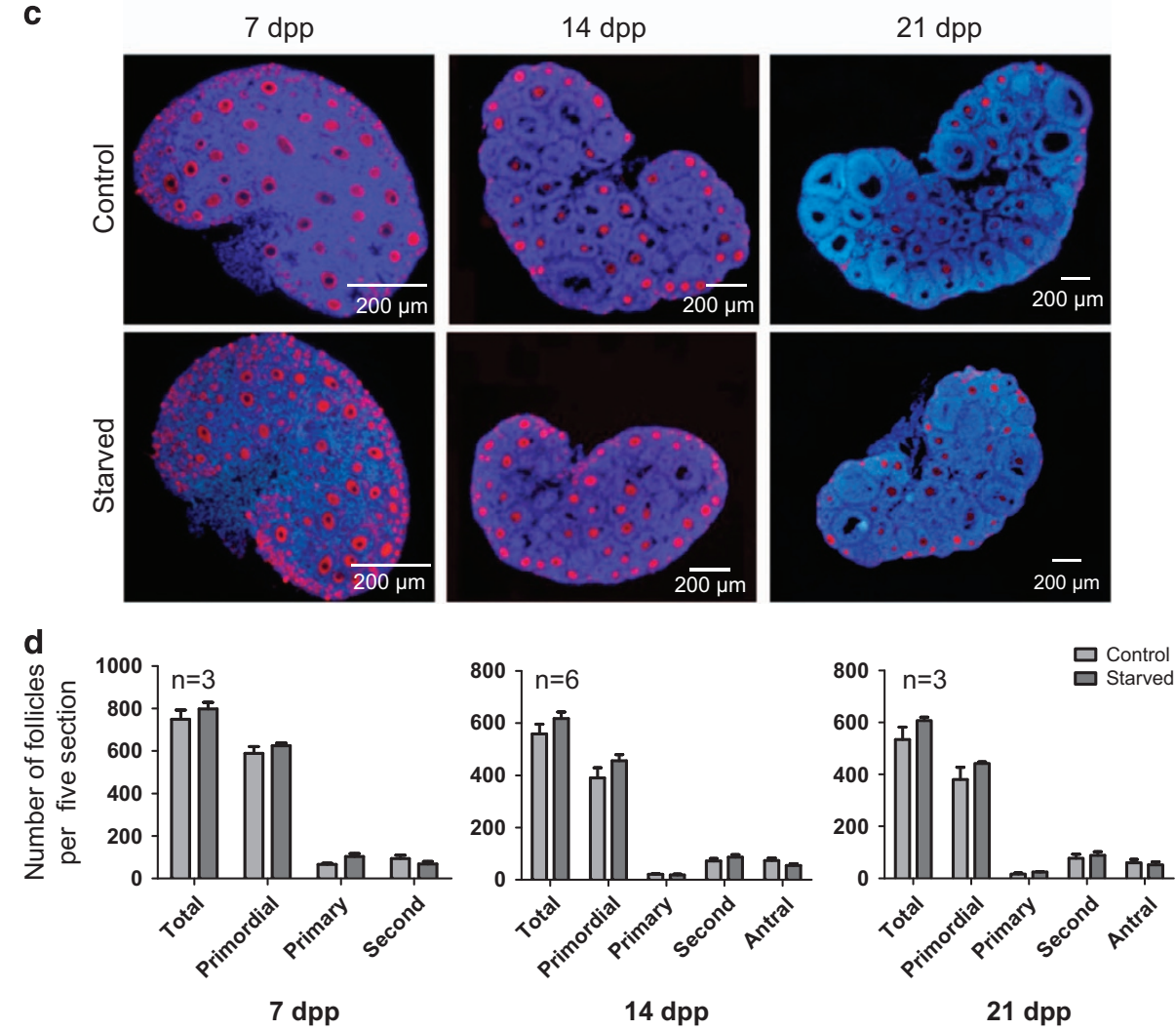

Figure 7 Reversibility of the starvation effect on the body size and ovarian follicle pool. (a) Starved pups compared with normal littermate after standard diet restoring. (b) Body weight and length of starved and control pups $(n=3)$. (c) Representative IF for the germ cell marker MVH in tissue sections of control and starved ovaries after 7 d.p.p., 14 d.p.p. and 21 d.p.p. from standard diet restoring. (d) Quantification of the number of primordial, primary, secondary and antral follicles in control and starved ovaries after 7 d.p. p., 14 d.p.p. and 21 d.p.p. from standard diet restoring. All the experiments were repeated at least three times. ${ }^{*} P<0.05 ;{ }^{* \star} P<0.01$ 
markers of oxidative stress, autophagy and apoptosis, increased in the starved ovaries. Despite these, the numbers of the remaining pre-granulosa cells and oocytes in such ovaries were apparently still sufficient to sustain the assembly of a normal number of follicles. Alternatively, this finding can be explained by the presence of ovarian or extra-ovarian stem cells able to sustain the ovary recovery. ${ }^{59,60}$

Dehydration might be a non-negligible factor in ovary molecular changes even though the starved pups rejected to suck water and the starvation time was not so long. The main objective of this investigation was to explore the effects of starvation and the influence of dehydration on mouse primordial follicles formation would be the next phase study. ${ }^{58,61}$

In conclusion, the present data indicate that nutrient deficiency at birth can generate a number of adaptive metabolic and oxidative responses in the ovaries causing increased apoptosis both in the somatic cells and oocyte and autophagy mainly in these latter and leading to impaired formation of the PF pool. Under the relatively short starvation time used by us ( $36 \mathrm{~h})$, possibly thanks to such adaptive response, the ovary maintains the capability of regaining a normal follicle pool.

\section{Materials and Methods}

Animals. CD1 mice were obtained from Vital River Laboratory Animal Technology Co. LTD (Beijing, China) and maintained in the animal room of Qingdao Agriculture University, ad libitum. Females were mated with males and the presence of the vaginal plug the morning after breeding, was considered as 0.5 day of pregnancy. For starvation protocols, pups were separated from mother at 1.5 d.p.p. for $36 \mathrm{~h}$. To make sure to use pups that have received the same nutrition level before starvation, only animals with the same body weight $(2.2 \pm 0.1 \mathrm{~g})$ were selected. All procedures involving animals were approved by the Institutional Animal Care and Use Committees of Qingdao Agricultural University.

Immunofluorescence. Ovaries were dissected and immediately fixed in $4 \%$ paraformaldehyde overnight. The samples were processed following standard histological procedures for paraffin embedding and serially sectioned at $5 \mu \mathrm{m}$. The sections were heated at $60^{\circ} \mathrm{C}$ in an air oven for $2 \mathrm{~h}$, then immediately washed in xylene and rehydrated through a graded series of ethanol and soaked in PBS. Finally, they were transferred in $0.01 \mathrm{M}$ sodium citrate buffer at high temperature $\left(95^{\circ} \mathrm{C}\right.$ ) for $10 \mathrm{~min}$. After $1 \mathrm{~h}$ blocking with BDT ( $3 \% \mathrm{BSA}, 10 \%$ normal goat serum in TBS), the sections were incubated with primary antibodies (Supplementary Table S2) in a humidified atmosphere overnight at $4{ }^{\circ} \mathrm{C}$. Cy3-labeled goat anti-rabbit or FITC-conjugated goat anti-mouse secondary antibodies were used at dilution of 1: 150 (Beyotime, A0516, A0568, Nantong, China) for $30 \mathrm{~min}$ at $37^{\circ} \mathrm{C}$ in the dark. Counterstaining was performed with Hoechst33342 (Beyotime, C1022) or $\mathrm{PI}$ (Abcam, Cambridge, UK, ab14083). Oocytes in cysts or into primordial follicles were scored in every third section as previously described. ${ }^{62,63}$

TUNEL assay. TUNEL-positive cells were detected in paraffin sections of ovaries using the Bright Red Apoptosis Detect Kit (Vazyme, A113-02, Nanjing, China). Briefly, the sections were heated at the $60^{\circ} \mathrm{C}$ in an air oven for $2 \mathrm{~h}$, then immediately washed in xylene and rehydration through a graded series of ethanol, and soaked in PBS. The samples were then treated with proteinase $\mathrm{K}$ for $15 \mathrm{~min}$ at room temperature, rinsed twice with PBS and incubated for $60 \mathrm{~min}$ at $37^{\circ} \mathrm{C}$ in the dark in $100 \mu \mathrm{l}$ of the TUNEL reaction mixture. Counterstaining was performed with Hoechst33342 (Beyotime, C1022).

Transmission electron microscopy. The ovaries were dissected and immediately fixed in $2.5 \%$ glutaraldehyde in $0.2 \mathrm{M} \mathrm{PBS}(\mathrm{pH}=7.2)$ overnight at $4{ }^{\circ} \mathrm{C}$. The samples were processed and included in epoxypropane resin following standard transmission electron microscopy (TEM) procedures. Serial sections were cut at $50 \mathrm{~nm}$ using the EM UC7 ultramicrotome (Leica, Germany), stained with lead citrate and uranium and observed under HT7700 transmission electron microscope.
WB analysis. Protein extracts were obtained from six ovaries and using the Cell Lysis Buffer for WB (Beyotime, P0013). The proteins were separated on 10\% SDSPAGE gel and transferred onto Immobilon-PSQ Transfer Membrane (Millipore MA, USA). After blocking, the membranes were incubated with the appropriate primary antibody (Supplementary Table S2) overnight at $4{ }^{\circ} \mathrm{C}$. After washing three times in Tris-buffered saline and Tween 20 (TBST), the membranes were incubated at $37^{\circ} \mathrm{C}$ for $2 \mathrm{~h}$ with horseradish peroxidase (HRP)-conjugated goat anti-rabbit (Beyotime, A0258) IgG or goat anti-mouse (Beyotime, A0216) lgG at 1:2000 dilution in TBST. Finally, the membranes were reacted with BeyoECL Plus Kit (Beyotime, P0018). $\beta$-Actin was used as housekeeping protein control.

RNA extraction and quantitative real-time PCR. The mRNA was retrieved from two ovaries using the RNA Prep Pure Micro Kit (Aidlab RN07, Beijing, China), according to the manufacturer's descriptions and then reverse-transcribed into cDNA using TransScript One-Step gDNA Removal and cDNA Synthesis SuperMix (TransGen Biotech AT311-03, Beijing, China). Thermal cycler program was set as $50 \mathrm{~min}$ at $42{ }^{\circ} \mathrm{C}, 65^{\circ} \mathrm{C}$ for $15 \mathrm{~min}$, and finally a cooling step at $4^{\circ} \mathrm{C}$. Quantitative PCR (Supplementary Table S1) was carried out with Light Cycler realtime PCR instrument (Roche, Basel, Switzerland, LC480) using a Light Cycler SYBR Green I Master (Roche, 04887352001). Gene expression changes were analyzed by the $2^{-\triangle \triangle \mathrm{Ct}}$ method and normalized to $\beta$-actin.

Dosage of blood amino acids and glucose. Samples of blood were collected from the mouse tail vein. For amino acid dosage, serum was separated from blood and de-proteinized with sulfosalicylic acid. Free amino acids in the supernatants were measured using an automated amino acid analyser (Hitachi L8900, Tokyo, Japan). Glucose concentrations were determined by dropping blood samples onto an Accu-Chek Active test strips (Roche, Mannheim, Germany) and measuring by AccuChek Active Blood Glucose Meter (Roche GC0612179, Basel, Switzerland).

Statistical analyses. T-test was used to assess the difference between two groups (normal distribution) ${ }^{40,47,64,65}$ and one-way analysis of variance (ANOVA) for multiple comparison tests to analyze the effects of starvation on BECLIN1 protein level in Supplementary Figure S3B in the ovary. Statistical analysis of follicle number counts was performed using Prism 5.0 (GraphPad Software Inc., San Diego, CA, USA).

\section{Conflict of Interest}

The author declares no conflict of interest.

Acknowledgements. This work was supported by National Natural Science Foundation of China (31471346 and 31671554), National Basic Research Program of China (973 Program, 2012CB944401), Natural Science Foundation of Shandong Province (ZR2013CQ029) and Research Program of Wuhan Polytechnic University (2016y30).

1. Pepling ME, Spradling AC. Female mouse germ cells form synchronously dividing cysts. Development 1998; 125: 3323-33328.

2. Greenbaum MP, Yan W, Wu MH, Lin YN, Agno JE, Sharma M et al. TEX14 is essential for intercellular bridges and fertility in male mice. Proc Natl Acad Sci USA 2006; 103: 4982-4987.

3. Greenbaum MP, Iwamori N, Agno JE, Matzuk MM. Mouse TEX14 is required for embryonic germ cell intercellular bridges but not female fertility. Biol Reprod 2009; 80: 449-457.

4. McLaren A. Meiosis and differentiation of mouse germ cells. Symp Soc Exp Biol 1984; 38: 7-23.

5. Tam PP, Snow MH. Proliferation and migration of primordial germ cells during compensatory growth in mouse embryos. J Embryol Exp Morphol 1981; 64: 133-147.

6. Lei L, Spradling AC. Mouse primordial germ cells produce cysts that partially fragment prior to meiosis. Development 2013; 140: 2075-2081.

7. Mahajan-Miklos S, Cooley L. Intercellular cytoplasm transport during Drosophila oogenesis. Dev Biol 1994; 165: 336-351.

8. Arama E, Agapite J, Steller H. Caspase activity and a specific cytochrome $\mathrm{C}$ are required for sperm differentiation in Drosophila. Dev Cell 2003; 4: 687-697.

9. Pepling ME, Wilhelm JE, O'Hara AL, Gephardt GW, Spradling AC. Mouse oocytes within germ cell cysts and primordial follicles contain a Balbiani body. Proc Natl Acad Sci USA 2007; 104: 187-192.

10. Lei $L$, Spradling AC. Mouse oocytes differentiate through organelle enrichment from sister cyst germ cells. Science 2016; 352: 95-99.

11. Pepling ME, Spradling AC. Mouse ovarian germ cell cysts undergo programmed breakdown to form primordial follicles. Dev Biol 2001; 234: 339-351.

12. Lobascio AM, Klinger FG, Scaldaferri ML, Farini D, De Felici M. Analysis of programmed cell death in mouse fetal oocytes. Reproduction 2007; 134: 241-252.

13. De Felici M, Lobascio AM, Klinger FG. Cell death in fetal oocytes: many players for multiple pathways. Autophagy 2008; 4: 240-242. 
14. Rodrigues $P$, Limback D, McGinnis LK, Plancha CE, Albertini DF. Multiple mechanisms of germ cell loss in the perinatal mouse ovary. Reproduction 2009; 137: 709-720.

15. Gawriluk TR, Hale AN, Flaws JA, Dillon CP, Green DR, Rucker EB 3rd. Autophagy is a cell survival program for female germ cells in the murine ovary. Reproduction 2011; 141: 759-765.

16. Giorgio M, Trinei M, Migliaccio E, Pelicci PG. Hydrogen peroxide: a metabolic by-product or a common mediator of ageing signals? Nat Rev Mol Cell Biol 2007; 8: 722-728.

17. Zhang X, Cheng X, Yu L, Yang J, Calvo R, Patnaik $S$ et al. MCOLN1 is a ROS sensor in lysosomes that regulates autophagy. Nat Commun 2016; 7: 12109.

18. Jones DP. Radical-free biology of oxidative stress. Am J Physiol Cell Physiol 2008; 295: C849-C868

19. Jones DP. Redefining oxidative stress. Antioxid Redox Signal 2006; 8: 1865-1879.

20. Zhang R, Liu H, Bai H, Zhang Y, Liu Q, Guan L et al. Oxidative stress status in Chinese women with different clinical phenotypes of polycystic ovary syndrome. Clin Endocrinol 2016; 86: 88-96.

21. Beyazit F, Yilmaz N, Balci O, Adam M, Yaman ST. Evaluation of oxidative stress in women with polycystic ovarian syndrome as represented by serum ischemia modified albumin and its correlation with testosterone and insulin resistance. Intern Med 2016; 55: 2359-2364.

22. Devine PJ, Perreault SD, Luderer U. Roles of reactive oxygen species and antioxidants in ovarian toxicity. Biol Reprod 2012; 86: 27.

23. Chen Y, Jefferson WN, Newbold RR, Padilla-Banks E, Pepling ME. Estradiol, progesterone, and genistein inhibit oocyte nest breakdown and primordial follicle assembly in the neonatal mouse ovary in vitro and in vivo. Endocrinology 2007; 148: 3580-3590.

24. Kipp JL, Kilen SM, Bristol-Gould S, Woodruff TK, Mayo KE. Neonatal exposure to estrogens suppresses activin expression and signaling in the mouse ovary. Endocrinology 2007; 148 : 1968-1976.

25. Iguchi T, Fukazawa Y, Uesugi Y, Takasugi N. Polyovular follicles in mouse ovaries exposed neonatally to diethylstilbestrol in vivo and in vitro. Biol Reprod 1990; 43: 478-484.

26. Honma S, Suzuki A, Buchanan DL, Katsu Y, Watanabe H, Iguchi T. Low dose effect of in utero exposure to bisphenol $\mathrm{A}$ and diethylstilbestrol on female mouse reproduction. Reprod Toxicol 2002; 16: 117-122

27. Karavan JR, Pepling ME. Effects of estrogenic compounds on neonatal oocyte development. Reprod Toxicol 2012; 34: 51-56.

28. Hahn KL, Johnson J, Beres BJ, Howard S, Wilson-Rawls J. Lunatic fringe null female mice are infertile due to defects in meiotic maturation. Development 2005; 132: 817-828.

29. Trombly DJ, Woodruff TK, Mayo KE. Suppression of Notch signaling in the neonatal mouse ovary decreases primordial follicle formation. Endocrinology 2009; 150: 1014-1024.

30. Manosalva I, Gonzalez A, Kageyama R. Hes1 in the somatic cells of the murine ovary is necessary for oocyte survival and maturation. Dev Biol 2013; 375: 140-151.

31. Xu J, Gridley T. Notch2 is required in somatic cells for breakdown of ovarian germ-cell nests and formation of primordial follicles. BMC Biol 2013; 11 : 13.

32. Wang J, Roy SK. Growth differentiation factor-9 and stem cell factor promote primordial follicle formation in the hamster: modulation by follicle-stimulating hormone. Biol Reprod 2004; 70: 577-585

33. Bedell MA, Brannan Cl, Evans EP, Copeland NG, Jenkins NA, Donovan PJ. DNA rearrangements located over $100 \mathrm{~kb} 5^{\prime}$ of the Steel (SI)-coding region in Steel-panda and Steel-contrasted mice deregulate $\mathrm{SI}$ expression and cause female sterility by disrupting ovarian follicle development. Genes Dev 1995; 9: 455-470.

34. Huang EJ, Manova K, Packer Al, Sanchez S, Bachvarova RF, Besmer P. The murine steel panda mutation affects kit ligand expression and growth of early ovarian follicles. Dev Biol 1993: 157: 100-109.

35. Bernstein A, Chabot B, Dubreuil $P$, Reith A, Nocka $\mathrm{K}$, Majumder $\mathrm{S}$ et al. The mouse W/c-kit locus. Ciba Found Symp 1990; 148: 158-166; discussion 166-172.

36. Dissen GA, Romero C, Hirshfield AN, Ojeda SR. Nerve growth factor is required for early follicular development in the mammalian ovary. Endocrinology 2001; 142: 2078-2086.

37. Kerr B, Garcia-Rudaz C, Dorfman M, Paredes A, Ojeda SR. NTRK1 and NTRK2 receptors facilitate follicle assembly and early follicular development in the mouse ovary. Reproduction 2009; 138: 131-140.

38. Spears N, Molinek MD, Robinson LL, Fulton N, Cameron H, Shimoda K et al. The role of neurotrophin receptors in female germ-cell survival in mouse and human. Development 2003; 130: 5481-5491.

39. Yan C, Wang P, DeMayo J, DeMayo FJ, Elvin JA, Carino C et al. Synergistic roles of bone morphogenetic protein 15 and growth differentiation factor 9 in ovarian function. Mol Endocrinol 2001; 15: 854-866.

40. Bristol-Gould SK, Kreeger PK, Selkirk CG, Kilen SM, Cook RW, Kipp JL et al. Postnatal regulation of germ cells by activin: the establishment of the initial follicle pool. Dev Biol 2006; 298: 132-148.

41. Cho BN, McMullen ML, Pei L, Yates CJ, Mayo KE. Reproductive deficiencies in transgenic mice expressing the rat inhibin alpha-subunit gene. Endocrinology 2001; 142: 4994-5004.

42. Kipp JL, Kilen SM, Woodruff TK, Mayo KE. Activin regulates estrogen receptor gene expression in the mouse ovary. J Biol Chem 2007; 282: 36755-36765.

43. Kimura F, Bonomi LM, Schneyer AL. Follistatin regulates germ cell nest breakdown and primordial follicle formation. Endocrinology 2011; 152: 697-706.
44. Wang Z, Niu W, Wang Y, Teng Z, Wen J, Xia G et al. Follistatin288 regulates germ cell cyst breakdown and primordial follicle assembly in the mouse ovary. PLoS one 2015; 10: 00129643.

45. Nilsson EE, Schindler R, Savenkova MI, Skinner MK. Inhibitory actions of Anti-Mullerian Hormone (AMH) on ovarian primordial follicle assembly. PLoS one 2011; 6: e20087.

46. Lei L, Jin S, Mayo KE, Woodruff TK. The interactions between the stimulatory effect of follicle-stimulating hormone and the inhibitory effect of estrogen on mouse primordial folliculogenesis. Biol Reprod 2010; 82: 13-22.

47. Niu W, Wang $Y$, Wang $Z$, Xin $Q$, Wang $Y$, Feng $L$ et al. JNK signaling regulates E-cadherin junctions in germline cysts and determines primordial follicle formation in mice. Development 2016; 143: 1778-1787.

48. Benedict JC, Lin TM, Loeffler IK, Peterson RE, Flaws JA. Physiological role of the aryl hydrocarbon receptor in mouse ovary development. Toxicol Sci 2000; 56: 382-388.

49. Robles R, Morita Y, Mann KK, Perez Gl, Yang S, Matikainen T et al. The aryl hydrocarbon receptor, a basic helix-loop-helix transcription factor of the PAS gene family, is required for normal ovarian germ cell dynamics in the mouse. Endocrinology 2000; 141: 450-453.

50. Soyal SM, Amleh A, Dean J. FIGalpha, a germ cell-specific transcription factor required for ovarian follicle formation. Development 2000; 127: 4645-4654.

51. Suzumori N, Yan C, Matzuk MM, Rajkovic A. Nobox is a homeobox-encoding gene preferentially expressed in primordial and growing oocytes. Mech Dev 2002; 111: 137-141.

52. Rajkovic A, Pangas SA, Ballow D, Suzumori N, Matzuk MM. NOBOX deficiency disrupts early folliculogenesis and oocyte-specific gene expression. Science 2004; 305: 1157-1159.

53. Uda M, Ottolenghi C, Crisponi L, Garcia JE, Deiana M, Kimber W et al. Foxl2 disruption causes mouse ovarian failure by pervasive blockage of follicle development. Hum Mol Genet 2004; 13: 1171-1181.

54. Wang N, Zhang P, Guo X, Zhou Z, Sha J. Hnrnpk, a protein differentially expressed in immature rat ovarian development, is required for normal primordial follicle assembly and development. Endocrinology 2011; 152: 1024-1035.

55. Xu B, Hua J, Zhang Y, Jiang X, Zhang H, Ma T et al. Proliferating cell nuclear antigen (PCNA) regulates primordial follicle assembly by promoting apoptosis of oocytes in fetal and neonatal mouse ovaries. PLOS ONE 2011; 6: e16046.

56. Barth JM, Szabad J, Hafen E, Kohler K. Autophagy in Drosophila ovaries is induced by starvation and is required for oogenesis. Cell Death Differ 2011; 18: 915-924.

57. Seidel HS, Kimble J. The oogenic germline starvation response in $\mathrm{C}$. elegans. PLoS one 2011; 6: e28074.

58. Kuma A, Hatano M, Matsui M, Yamamoto A, Nakaya $H$, Yoshimori $T$ et al. The role of autophagy during the early neonatal starvation period. Nature 2004; 432: 1032-1036.

59. Johnson J, Bagley J, Skaznik-Wikiel M, Lee HJ, Adams GB, Niikura $Y$ et al. Oocyte generation in adult mammalian ovaries by putative germ cells in bone marrow and peripheral blood. Cell 2005; 122: 303-315.

60. Zou K, Yuan Z, Yang Z, Luo H, Sun K, Zhou L et al. Production of offspring from a germline stem cell line derived from neonatal ovaries. Nat Cell Biol 2009; 11: 631-636.

61. Song ZH, Yu HY, Wang P, Mao GK, Liu WX, Li MN et al. Germ cell-specific Atg7 knockout results in primary ovarian insufficiency in female mice. Cell Death Dis 2015; 6: e1589.

62. Zhang H, Liu K. Cellular and molecular regulation of the activation of mammalian primordia follicles: somatic cells initiate follicle activation in adulthood. Hum Reprod Update 2015; 21 : 779-786.

63. Zhang XF, Zhang LJ, Li L, Feng YN, Chen B, Ma JM et al. Diethylhexyl phthalate exposure impairs follicular development and affects oocyte maturation in the mouse. Environ $\mathrm{Mol}$ Mutagen 2013; 54: 354-361.

64. Jones RL, Pepling ME. Role of the antiapoptotic proteins BCL2 and MCL1 in the neonatal mouse ovary. Biol Reprod 2013; 88: 46.

65. Linher K, Dyce P, Li J. Primordial germ cell-like cells differentiated in vitro from skin-derived stem cells. PLOS ONE 2009; 4: e8263.

Cell Death and Disease is an open-access journal published by Nature Publishing Group. This work is licensed under a Creative Commons Attribution 4.0 International License. The images or other third party material in this article are included in the article's Creative Commons license, unless indicated otherwise in the credit line; if the material is not included under the Creative Commons license, users will need to obtain permission from the license holder to reproduce the material. To view a copy of this license, visit http://creativecommons.org/licenses/by/4.0/

(C) The Author(s) 2017 